\title{
Altitude registration of limb-scattered radiation
}

\author{
Leslie Moy ${ }^{1}$, Pawan K. Bhartia ${ }^{2}$, Glen Jaross ${ }^{2}$, Robert Loughman $^{3}$, Natalya Kramarova ${ }^{1}$, Zhong Chen ${ }^{1}$, \\ Ghassan Taha ${ }^{4}$, Grace Chen ${ }^{1}$, and Philippe $\mathrm{Xu}^{5}$ \\ ${ }^{1}$ Science Systems and Applications, Inc. (SSAI), 10210 Greenbelt Road, Suite 600, Lanham, Maryland 20706, USA \\ ${ }^{2}$ NASA Goddard Space Flight Center, Greenbelt, Maryland, USA \\ ${ }^{3}$ Hampton University, Hampton, Virginia, USA \\ ${ }^{4}$ GESTAR, Columbia, Maryland, USA \\ ${ }^{5}$ Science Applications International Corporation (SAIC), Lanham, Maryland, USA
}

Correspondence to: Leslie Moy (leslie.moy@ssaihq.com)

Received: 28 March 2016 - Published in Atmos. Meas. Tech. Discuss.: 8 June 2016

Revised: 30 November 2016 - Accepted: 19 December 2016 - Published: 12 January 2017

\begin{abstract}
One of the largest constraints to the retrieval of accurate ozone profiles from UV backscatter limb sounding sensors is altitude registration. Two methods, the Rayleigh scattering attitude sensing (RSAS) and absolute radiance residual method (ARRM), are able to determine altitude registration to the accuracy necessary for long-term ozone monitoring. The methods compare model calculations of radiances to measured radiances and are independent of onboard tracking devices. RSAS determines absolute altitude errors, but, because the method is susceptible to aerosol interference, it is limited to latitudes and time periods with minimal aerosol contamination. ARRM, a new technique introduced in this paper, can be applied across all seasons and altitudes. However, it is only appropriate for relative altitude error estimates. The application of RSAS to Limb Profiler (LP) measurements from the Ozone Mapping and Profiler Suite (OMPS) on board the Suomi NPP (SNPP) satellite indicates tangent height $(\mathrm{TH})$ errors greater than $1 \mathrm{~km}$ with an absolute accuracy of $\pm 200 \mathrm{~m}$. Results using ARRM indicate a $\sim 300$ to $400 \mathrm{~m}$ intra-orbital TH change varying seasonally $\pm 100 \mathrm{~m}$, likely due to either errors in the spacecraft pointing or in the geopotential height $(\mathrm{GPH})$ data that we use in our analysis. ARRM shows a change of $\sim 200 \mathrm{~m}$ over $\sim 5$ years with a relative accuracy (a long-term accuracy) of $\pm 100 \mathrm{~m}$ outside the polar regions.
\end{abstract}

\section{Introduction}

Instruments that measure the solar radiation scattered by the Earth's atmosphere in the limb direction provide a low-cost way of measuring trace gases, aerosol profiles, and clouds from satellites. The technique can provide daily full coverage of the sunlit Earth from commonly used polar sunsynchronous satellites. To meet long-term ozone monitoring needs ( $3 \%$ precision between 15 and $50 \mathrm{~km}$ ) requires the altitude registration of the radiances to be accurate to within $\sim 100 \mathrm{~m}$ (Jaross et al., 2014). For a sensor orbiting at $800 \mathrm{~km}$, this translates into $\sim 6$ arcsec accuracy in the pointing direction of the instrument line of sight (LOS) with respect to Earth's horizon. This is often a difficult goal to achieve.

In this paper we critically examine the performance of two methods of altitude registration that compare measured and simulated radiances. We discuss the inherent strengths and limitations of each method and then assess their performance using data from the Ozone Mapping and Profiler Suite (OMPS) Limb Profiler (LP), launched on board the Suomi NPP (SNPP) satellite on 28 October 2011.

One of these techniques, known as Rayleigh scattering attitude sensing (RSAS), is relatively insensitive to instrument radiometric errors because it utilizes measurements at two altitudes $(20$ and $40 \mathrm{~km})$ where many of the errors are correlated. However, since the method uses limb radiances measured at $20 \mathrm{~km}$, it is greatly affected by aerosols and therefore works best where there is minimal aerosol loading. Under these conditions the accuracy of the method is limited by the accuracy of the geopotential height (GPH) data 
near $3 \mathrm{hPa}(\sim 40 \mathrm{~km})$. Since aerosol contamination limits the range of latitudes and times where RSAS can be applied, we developed the absolute radiance residual method (ARRM). ARRM excels in relative rather than absolute limb altitude registration.

We describe the theoretical basis of these two techniques in Sect. 2 and their application to the OMPS LP instrument in Sect. 3. We present several validations of our uncertainty estimates in Sect. 4 and summarize our findings in Sect. 5.

\section{Theoretical basis}

Most scene-based altitude registration methods applied to limb-scattering instruments take advantage of the fact that the atmospheric Rayleigh scattering measured by these instruments varies by $12-14 \% \mathrm{~km}^{-1}$. For wavelengths longer than $310 \mathrm{~nm}$, the limb-scattered (LS) radiance has a significant contribution from diffuse upwelling radiance (DUR), which is affected by tropospheric clouds, aerosols, and surface albedos within a circular cone whose base extends hundreds of kilometers to the horizon. The further these reflectors are from the apex of the cone, the less is their contribution to DUR. At non-ozone-absorbing wavelengths DUR can be as much as half of the measured radiance. Since DUR is challenging to model accurately, all successful altitude registration methods must be relatively insensitive to reflectivity variations within the cone.

The RSAS method, described in Sect. 2.1, employs signal ratios in which the DUR effects largely cancel. ARRM, described in Sect. 2.2, uses $295 \mathrm{~nm}$ radiances for which ozone absorption screens the DUR signal. The knee method, described in Sect. 2.3, has been used extensively by others (Sioris et al., 2003; Kaiser et al., 2004; Rault, 2005; von Savigny et al., 2005; Taha et al., 2008), but our analysis indicates that it offers no advantages over RSAS and ARRM.

\subsection{Rayleigh scattering attitude sensor (RSAS) method}

This technique is named after the sensor that was flown on the Space Shuttle STS-72 in January 1996 (Janz et al., 1996) to test a concept originally proposed by Bhartia in 1992 . The technique takes advantage of the fact that the gradient in the $\log$ of the LS radiance $I$ with altitude $z, \operatorname{d} \ln I / \mathrm{d} z$, changes by a factor of 3 between 40 and $20 \mathrm{~km}$ for wavelengths near $350 \mathrm{~nm}$ (Fig. 1). This is caused by the exponentially increasing attenuation of Rayleigh scattering with pressure. At $40 \mathrm{~km}$ this attenuation is small, and when aerosol loading is minimal, $\mathrm{d} \ln \mathrm{I} / \mathrm{dz}$ is largely determined by $\mathrm{d} \ln P / \mathrm{d} z$, where $P$ is the atmospheric pressure at altitude $z$. However, at $20 \mathrm{~km}$ the extinction and scattering at $350 \mathrm{~nm}$ are nearly equal, which means limb radiances from this altitude are relatively insensitive to the exact altitude of the tangent point. The tangent point is where the sensor line of sight (LOS) intersects the Earth radius vector at a right angle. Though sev-
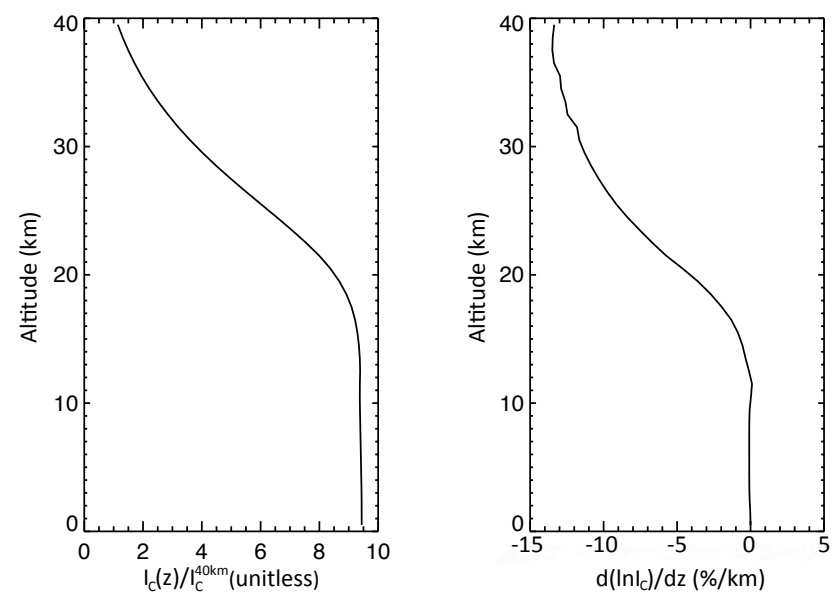

Figure 1. Left panel shows calculated $350 \mathrm{~nm}$ radiances as a function of altitude, normalized at $40.5 \mathrm{~km}$. The GSLS calculation models the OMPS LP field of view without aerosols. The shape of the curve originates from the competition between molecular scattering, which increases roughly linearly with pressure, and attenuation, which becomes important when the Rayleigh optical thicknesses near the tangent point start to become large. Attenuation causes the slope of $350 \mathrm{~nm}$ radiances to change sharply between 40 and $20 \mathrm{~km}$ (right panel), a $\sim 10 \% \mathrm{~km}^{-1}$ difference between 20 and $40 \mathrm{~km}$. The slope is used to estimate altitude registration errors by comparing measured ratios with model simulated ratios.

eral variations of the RSAS technique have been developed for ozone sensors (McPeters et al., 2000; Rault, 2005; Taha et al., 2008), we find that the simplest formulation described below works as well as any other.

If $r$ is the ratio of radiances for wavelength $\lambda$ at altitudes $z_{1}$ and $z_{2}$, and $s_{1}$ and $s_{2}$ are the vertical slopes $\operatorname{dln} I / \mathrm{d} z$ at those altitudes, then the error in tangent height (TH) can be calculated as follows:

$\Delta z=-\frac{\ln (r)_{\mathrm{m}}-\ln (r)_{\mathrm{c}}}{s\left(z_{1}\right)-s\left(z_{2}\right)}$,

where the subscript " $m$ " refers to the measured radiance ratios, and "c" refers to the ratio calculated using a radiative transfer model. To get the most accurate estimate of TH error, the denominator should be as large as possible, and the uncertainties in estimating the numerator should be small. The smallest uncertainties in the numerator occur at wavelengths near $350 \mathrm{~nm}$, where trace gas absorption and aerosol scattering effects are small. Setting $z_{1}$ to be near $40 \mathrm{~km}$ and $z_{2}$ to be at or below $20 \mathrm{~km}$ maximizes the value of the denominator, typically near $0.10 \mathrm{~km}^{-1}$. An accuracy of 0.01 (equal to $1 \%$ in radiance ratios) is therefore needed to estimate $\mathrm{TH}$ within $100 \mathrm{~m}$.

Figure 2 shows $352 \mathrm{~nm}$ sun-normalized radiances from one orbit of OMPS LP when the global aerosol loading is small. The short-scale features at 20.5 and $40.5 \mathrm{~km}$ are largely caused by variations in cloud and surface albedo. The $20.5 \mathrm{~km}$ curve has sharper features and appears to be shifted 


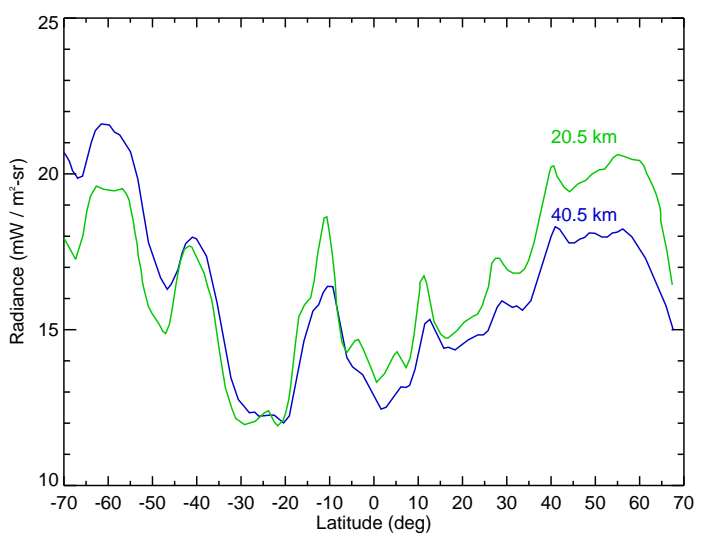

Figure 2. The $350 \mathrm{~nm}$ sun-normalized radiances from one orbit of OMPS LP (center slit) taken on 2 February 2012. The blue line shows $40.5 \mathrm{~km}$ values, and the green line shows $20.5 \mathrm{~km}$ values (divided by 8 to put both curves on a similar scale) versus latitude. Since the global aerosol loading on this day was small, the shortscale features in both curves are largely caused by variations in cloud and surface albedo. The $20.5 \mathrm{~km}$ curve has sharper features and appears to be shifted toward the South Pole. This is because large Rayleigh attenuation at $20.5 \mathrm{~km}$ causes the radiances to have much higher sensitivity to the atmosphere on the satellite side of the tangent point (TP), while $40.5 \mathrm{~km}$ radiances have similar sensitivities to both sides. This effect creates large noise in applying the RSAS technique to orbital data. However, since the noise varies randomly from orbit to orbit, it can be reduced by averaging data from multiple orbits.

toward the South Pole. This is because large Rayleigh attenuation at $20.5 \mathrm{~km}$ causes the radiances to have much higher sensitivity to the atmosphere on the satellite side of the tangent point (TP), while the $40.5 \mathrm{~km}$ radiances have similar sensitivities to both sides. This effect creates large noise in applying the RSAS technique to orbital data. However, since the noise varies randomly from orbit to orbit, DUR modeling errors are reduced by averaging data from multiple orbits (this is confirmed in daily averages of the sun-normalized radiances where short-scale features are not seen).

Aerosols in the instrument's LOS are a more significant source of error for the RSAS method. Though the effect of aerosols near $350 \mathrm{~nm}$ is small compared to longer wavelengths, it is difficult to model due to subtle differences between two large effects: the reduction of Rayleigh scattering by aerosol extinction and the enhancement of limb radiances by aerosol scattering. Figure 3 shows the ratio of $350 \mathrm{~nm}$ limb-scattered radiances at $20.5 \mathrm{~km}$ with and without aerosols as a function of latitude. The strong latitude dependence is caused by an order-of-magnitude change in the aerosol scattering phase function with latitude combined with the attenuation of Rayleigh-scattered radiation by aerosols along the LOS. In the Southern Hemisphere, where LP measures backscattered radiation, the latter effect dominates and the radiation decreases. The net effect is difficult

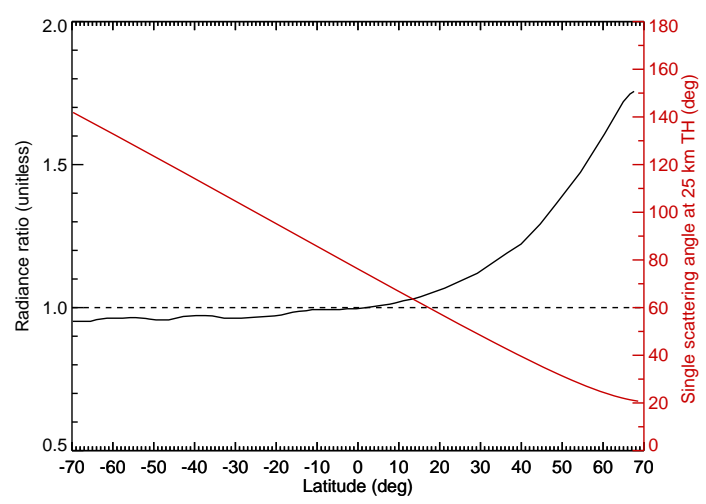

Figure 3. The GSLS-modeled ratio of $350 \mathrm{~nm}$ limb-scattered radiances at $20.5 \mathrm{~km}$ with and without aerosols (left axis) and singlescattering angle (right axis) as a function of latitude. A nominal latitude-independent aerosol extinction profile was used in the calculation for the OMPS LP viewing geometry on 2 February 2012. The strong latitude dependence is caused by an order of magnitude change in aerosol scattering phase function with latitude combined with the attenuation of Rayleigh-scattered radiation by aerosols along the line of sight (LOS). In the Southern Hemisphere, where LP measures aerosols in the backscatter direction, the latter effect dominates and the radiation decreases. The net effect is very sensitive to altitude, variation of aerosol extinction profile along the LOS, and aerosol particle size distribution, and it is therefore difficult to calculate accurately.

to calculate accurately since it is very sensitive to aerosol altitude, variation of the aerosol extinction profile along the LOS, and aerosol particle size distribution. Model calculations with and without an average loading of aerosols erroneously attribute TH errors of $\sim 100 \mathrm{~m}$ in the Southern Hemisphere and $\sim 200 \mathrm{~m}$ in the Northern Hemisphere.

Though the effect of aerosols is similar to the cloud effect mentioned earlier, it is not random because aerosols tend to have systematic latitudinal variability at these altitudes we consider. Given this complexity, the RSAS method works best in latitudes and months where the $350 \mathrm{~nm}$ aerosol extinction at $20 \mathrm{~km}$ is relatively small.

Another potential source of uncertainty in applying the RSAS technique comes from uncertainty in simulating radiances at $40 \mathrm{~km}$; one needs to have accurate pressure profiles for altitudes at and above $40 \mathrm{~km}$. If the pressure profiles are obtained from GPH profiles provided by meteorological data assimilation systems, a one-to-one relationship exists between the two errors: a $100 \mathrm{~m}$ error in GPH at $3 \mathrm{hPa}$ translates into $\sim 100 \mathrm{~m}$ error in determining TH altitude. RSAS is not sensitive to GPH errors that are independent of altitude.

\subsection{Absolute radiance residual method (ARRM)}

We developed ARRM to be applicable over many latitudes and times. In part this method uses radiances measured by a limb instrument near $295 \mathrm{~nm}$ at $\sim 65 \mathrm{~km}$ to determine altitude error. With the exception of polar mesospheric 
clouds (PMCs), the atmosphere is typically free of particulate matter at $65 \mathrm{~km}$. PMCs, which form in the polar summer and are typically located at $80 \mathrm{~km}$, can significantly affect $65 \mathrm{~km}$ limb radiances if they are in the LOS of the instrument. Fortunately most of the PMC contamination is screened using a $350 \mathrm{~nm}$ channel radiance residual flag at $65 \mathrm{~km}$.

Though $295 \mathrm{~nm}$ radiances can be very ozone sensitive, this sensitivity drops to less than $0.2 \%$ for a $10 \%$ change in ozone above $65 \mathrm{~km}$ because the ozone density at high altitudes is exceedingly low. At this altitude the ozone concentration typically changes by $25 \%$ per kilometer, so model radiance errors will be within $0.5 \%$ provided the OMPS TH is accurate to $1 \mathrm{~km}$.

A difficulty in applying ARRM is the inaccuracy of GPH data near $0.1 \mathrm{hPa}$ needed to calculate $295 \mathrm{~nm}$ radiances at $65 \mathrm{~km}$. GPH uncertainty increases with increased altitude (Schwartz et al., 2008). To reduce the effect of GPH inaccuracies, we developed a variation of a technique that has been used for many years to derive mesospheric temperature profiles from the vertical slope of Rayleigh-scattered radiances measured by ground-based UV lidars (McGee et al., 1991). The technique described in their paper computes temperatures using the relative density differences between successive altitudes where the scattering mechanism is purely Rayleigh. Since we rely on the same region of Rayleigh dominance, we can apply their technique to correct for errors in the GPH assumptions. GPH is related to temperature by assuming hydrostatic balance. The 350 and $295 \mathrm{~nm}$ residuals are affected similarly by the errors in the GPH with altitude, so we use the $350 \mathrm{~nm}$ residual to correct for the GPH errors at $295 \mathrm{~nm}$. To the extent that stray light is also wavelength independent, this correction will remove stray-light errors.

The residual at wavelength $\lambda$ at altitude $z$, defined as $\mathrm{d}(\lambda$, $z)=\ln I_{\mathrm{m}}(\lambda, z)-\ln I_{\mathrm{c}}(\lambda, z)$, is corrected using $350 \mathrm{~nm}$ residuals:

$\mathrm{d}_{\text {corr }}(\lambda, z)=\mathrm{d}(\lambda, z)-\left[\mathrm{d}(350, z)-\mathrm{d}\left(350, z_{0}\right)\right]$,

where $z_{0}$ is a normalization altitude.

The $350 \mathrm{~nm}$ differential residuals on the right side of Eq. (2) provide an estimate of the relative error in calculating radiances using meteorological data between $z$ and $z_{0}$. In effect we are limiting our sensitivity to GPH errors at $65 \mathrm{~km}$ by shifting our reliance on GPH assumptions to $40 \mathrm{~km}$. Since GPH error is wavelength independent, we can use this term to correct the residuals at any wavelength, assuming that the meteorological data at $z_{0}$ are accurate and that the $350 \mathrm{~nm}$ wavelength is well calibrated versus altitude. The large response of OMPS LP at $350 \mathrm{~nm}$ results in signals that are the least affected by out-of-band stray light.

The TH error estimated using this method is given by

$$
\Delta z=\frac{\mathrm{d}_{\text {corr }}(\lambda, z)}{s(\lambda, z)-\left[s(350, z)-s\left(350, z_{0}\right)\right]} .
$$

To summarize, in the application of ARRM we use $295 \mathrm{~nm}$ radiance residuals at $65 \mathrm{~km}$, adjusted with $350 \mathrm{~nm}$ differential
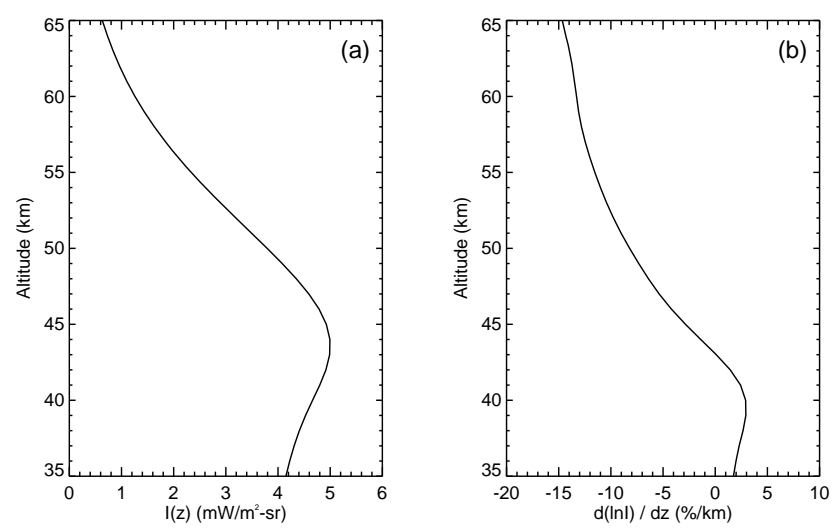

Figure 4. (a) shows GSLS-model-calculated $305 \mathrm{~nm}$ radiances as a function of altitude assuming an atmosphere with no aerosols. The slope (b) is caused by competition between Rayleigh scattering and ozone absorption near the altitude of maximum radiance, $\sim 44 \mathrm{~km}$. Above $55 \mathrm{~km}$ the sensitivity is nearly constant in height, $\sim 14 \% \mathrm{~km}^{-1}$ at $65 \mathrm{~km}$. Above the knee the radiances decrease with altitude due to the exponential decrease in Rayleigh scattering and ozone density. Below the knee the ozone absorption becomes so large that it essentially blocks most of the Rayleigh-scattered radiation from reaching the satellite, making the radiances insensitive to atmospheric pressure. This characteristic knee shape allows one to estimate altitude registration error in a manner very similar to that of RSAS, but it also makes it is very susceptible to ozone profile assumptions, as illustrated in Fig. 5.

residuals. The choice of a wavelength shorter than $300 \mathrm{~nm}$ minimizes sensitivity to ozone profile and DUR modeling. Though it is best to set $z_{0}$ as low as possible to minimize GPH-caused errors, aerosol contamination limits it to around $40 \mathrm{~km}$.

ARRM has two primary drawbacks. ARRM uses $350 \mathrm{~nm}$ differential residuals to correct for GPH errors between 40 and $65 \mathrm{~km}$, so like RSAS this method is sensitive to errors in GPH profiles near $3 \mathrm{hPa}$. To the extent these errors are time-invariant, ARRM works best to monitor changes in the TH error. ARRM is also sensitive to instrument calibration: a $1 \%$ error in radiance calibration at $65 \mathrm{~km}$ produces $\sim 70 \mathrm{~m}$ of error in determining the TH. It is therefore important that instrument calibration drifts are understood and corrected.

\section{3 "Knee method"}

The name of this method is derived from the characteristic knee shape of the limb radiance profiles (Fig. 4). Above the knee the radiances decrease with altitude due to the exponential decrease in Rayleigh scattering and ozone density. Below the knee ozone absorption becomes so large that it essentially blocks most of the Rayleigh-scattered radiation from reaching the satellite, making the radiances insensitive to atmospheric pressure. This characteristic shape allows estimations of altitude registration error in a manner very similar to that 
of RSAS. An advantage of this method is the ability to use shorter wavelengths that are less sensitive to aerosols.

A disadvantage is the method requires accurate ozone and pressure profiles near and above the knee region. A rough estimate of the ozone profile error caused by a TH error can be determined by simply shifting an ozone profile up and down (Fig. 5). From this analysis, errors in the ozone profile are found to be within $8 \%$ at $40 \mathrm{~km}$ from TH errors of $300 \mathrm{~m}$. It is important to note that the shift of the ozone profile does not necessarily translate to the exact error in altitude registration for limb radiances due to the nonlinearity of the inversion, which is especially important below $20 \mathrm{~km}$. Differences of $8 \%$ between the various ozone profile measurements are not unusual, and this will directly translate to uncertainty in the knee method.

The method also has a sensitivity to GPH errors that are similar to RSAS and ARRM. In our view this method provides no compelling advantage over a direct comparison between the limb ozone profile and a truth profile. Indeed, direct ozone comparisons are simpler and more reliable if the altitude registration error is the largest error source, and we use this technique to evaluate the results of RSAS and ARRM in Sect. 4.

\section{Results}

In this section we discuss altitude registration errors for the OMPS LP. Shortly after launch, RSAS analysis indicated a $\sim 2 \mathrm{~km}$ TH mis-registration, prompting an evaluation of pointing changes internal to the sensor. This evaluation relies on the image of the slit at the focal plane. Its description in Sect. 3.1 is included for completeness in describing the OMPS LP TH registration determination but is not necessarily applicable to other limb-scattering sensors. Subsequent RSAS analysis (after the application of the slit image results) is described in Sect. 3.2. OMPS LP Version 2.0 data have these RSAS results incorporated. ARRM results (Sect. 3.3) provide relative TH error estimates and are shown normalized to the secondary RSAS results. The magnitude of the ARRM results are within our uncertainty and were not incorporated in our latest data release.

An observed OMPS LP altitude error of $1 \mathrm{~km}$ translates to an along-track pointing error of $250 \mathrm{~m}$ for nadir-looking instruments. A positive TH error (the sensor is aimed higher than the indicated geolocation) means the nadir footprint is further south than believed.

\subsection{Slit edge results}

Slit edge analysis is a method of deriving pointing errors internal to the instrument, much like onboard star trackers. The analysis was performed early in the S-NPP mission and found to be extremely robust; subsequent slit edge analyses
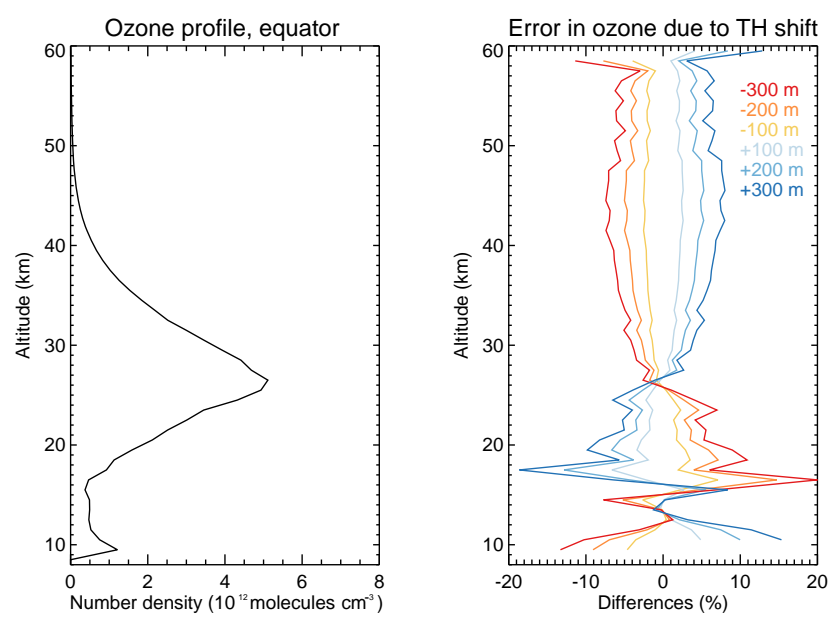

Figure 5. Typical ozone profile in the tropics (left panel). By shifting the ozone profile, we can estimate an order and pattern of error in ozone profiles due to TH shift (right panel). Errors in ozone retrievals are within $8 \%$ at $40 \mathrm{~km}$ from TH errors of $300 \mathrm{~m}$. Errors are least sensitive at the ozone peak $(25$ and $30 \mathrm{~km})$ and are more variable below. It is important to note that the shift of the ozone profile does not necessarily translate to the same error in altitude registration for limb radiances due to the nonlinearity of the inversion, which is especially important at lower altitudes (below $20 \mathrm{~km}$ ).

indicate that there have been no changes from initial results to date.

The OMPS LP sensor utilizes a two-dimensional chargecoupled device (CCD) detector to capture spectrally dispersed (along the 740-pixel row dimension) and vertically distributed (along the 340-pixel column dimension) radiation (Fig. 6). Three long vertical entrance slits spaced $4.25^{\circ}$ apart produce three distinct images of the atmosphere that are collected simultaneously on the single CCD. The resulting limb radiance profile from the center slit is aligned very closely to the satellite ground track, with tangent points trailing approximately $3000 \mathrm{~km}$ south of the sub-satellite point. The east and west slit images are separated in longitude by $2.25^{\circ}(250 \mathrm{~km}$ at their tangent points) from that of the center slit.

An unexpected thermal sensitivity was discovered in the LP instrument soon after launch (Jaross et al., 2014). Expansion of the LP instrument's entrance baffle as the sun illuminates it midway through the Northern Hemisphere causes mirrors in the telescope to rotate slightly, which in turn moves the limb radiance image on the detector. Since there are separate mirrors for each entrance slit, the three slit images move independently. These image motions cause misregistration of both the vertical pointing and center wavelength of each pixel. Vertical pointing changes are detected most clearly by observing the location (detector column) of the lower slit edge, which has a sharp signal gradient. Figure 7 contains plots of the average edge locations in the vertical (altitude) dimension along the orbit. These pointing shifts 


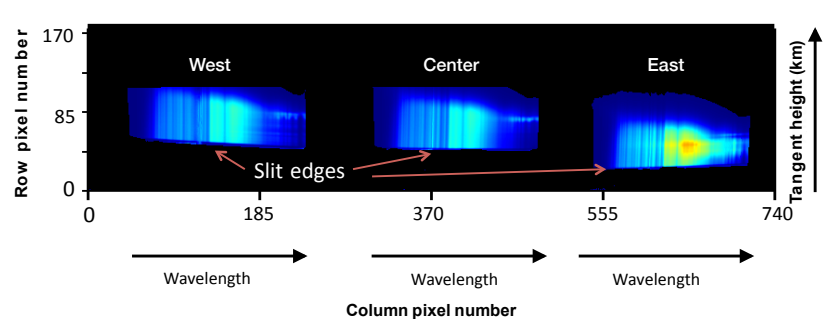

Figure 6. OMPS LP CCD high-gain Earth-viewing radiance images for the three slits (east/center/west). The east and west slit images are separated in longitude by $2.25^{\circ}$ from that of the center slit. The wavelength range for each image is 270 to $1050 \mathrm{~nm}$, and the minimal TH range is 0 to $80 \mathrm{~km}$. The CCD has 740 pixels in the wavelength dimension. There are 340 pixels in the spatial dimension; the high-gain images occupy the lower half of the CCD (pixels 0 to 170). The spatial extent of each slit's image on the detector is limited by the vertical length of that slit. The lower slit edges (nearest the Earth surface) provide a high-contrast signal cutoff that can be monitored for movement.

are very repeatable (ranging only $\pm 15 \mathrm{~m}$ at a given point in the orbit over a year).

Since the same slit edge analysis can be applied to prelaunch test data, it is possible to obtain the pixel line-of-sight shift relative to its calibrated value in the spacecraft reference frame. There is no evidence of image distortion, so this shift is the same for all detector pixels within a slit image. The edge analysis indicates the three slit edges shifted by the equivalent of 570, 470, and $950 \mathrm{~m}$ (east, center, and west slits, respectively) at the middle of an orbit relative to pre-launch measurements. A mean sensor temperature decrease exceeding $25^{\circ} \mathrm{C}$ from ground to on-orbit conditions is the suspected cause. We believe there are no additional uncorrected pointing shifts arising from within the LP instrument. An error or change in the alignment of the instrument with respect to $S / C$ axes is not detectable using this method.

After the application of the slit edge determined corrections, analysis of RSAS and ARRM results indicated remaining TH errors. These remaining errors are presented in the next two sections.

\subsection{RSAS results}

We use the Gauss-Seidel limb-scattering (GSLS) radiative transfer code described by Loughman et al. (2015) to estimate $350 \mathrm{~nm}$ radiances. Since the $40 / 20 \mathrm{~km}$ radiance ratio is not sensitive to polarization effects, we use the faster scalar code rather than the full vector one to calculate DUR in our model. The calculations assume a pure Rayleigh atmosphere bounded by a Lambertian reflecting surface at $1013.25 \mathrm{hPa}$. The reflectivity of this surface is calculated using limb measurements at $40 \mathrm{~km}$. However, both measurements and calculations show that the ratio of $40 / 20 \mathrm{~km}$ radiances is not affected by reflectivity or surface pressure and that there is no discernible cloud effect. Since $\mathrm{NO}_{2}$ only has a very small

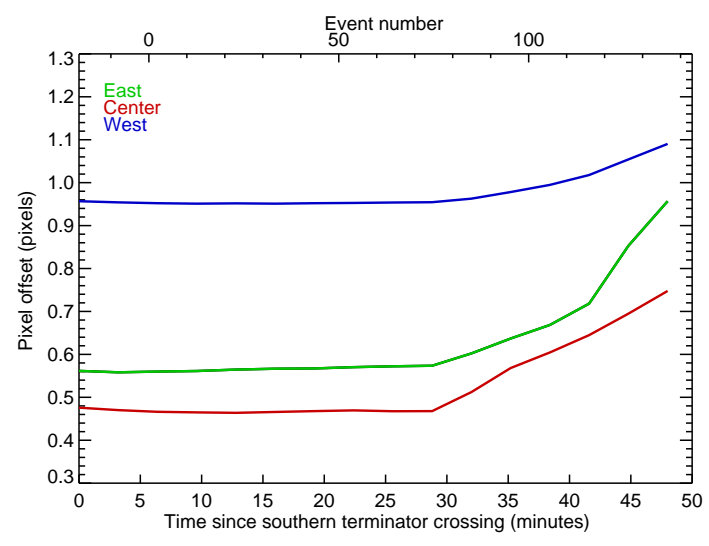

Figure 7. Slit edge results for the three slits (green: east slit; red: center slit; blue: west slit) plotted against time since southern terminator crossing. A 1-pixel shift corresponds to a $965 \mathrm{~m} \mathrm{TH}$ shift. The offsets are stable from the southern terminator to the midlatitude Northern Hemisphere, where the exposure to the sun increases thermal effects. The event number, which is an index of LP measurements through each orbit, is shown at the top.

$(<0.5 \%)$ effect on $350 \mathrm{~nm}$ radiances, climatological $\mathrm{NO}_{2}$ profiles are sufficient for the calculation. As described above, the RSAS method is not sensitive to ozone assumptions.

We estimate pressure and temperature vs. altitude at the LP measurement locations and time from the Modern-Era Retrospective Analysis for Research and Application (MERRA) data (GEOS-5 FP_IT Np) from the Global Modeling and Assimilation Office (GMAO) at NASA Goddard Space Flight Center (GSFC). The data are provided as GPH at 42 pressures from the surface to $0.1 \mathrm{hPa}$, on a $0.5^{\circ}$ latitude $\times 0.625^{\circ}$ longitude horizontal resolution grid, and at a $3 \mathrm{~h}$ interval. The GPH is converted to geometric height using a standard formula that takes into account the variation of gravity with latitude and elevation. Above $0.1 \mathrm{hPa}$ the temperature profile is extrapolated up to $80 \mathrm{~km}$ assuming a constant lapse rate of $-1.5 \mathrm{~K} \mathrm{~km}^{-1}$. The corresponding pressure profile is then calculated assuming hydrostatic equilibrium.

As discussed in Sect. 2.1, RSAS results are affected by aerosols near $20 \mathrm{~km}$. Aerosol profiles derived from the Optical Spectrograph and InfraRed Imaging System (OSIRIS) data (Llewellyn et al, 2004; Bourassa et al., 2007) indicate that tropical aerosols reached a minimum value (during the OMPS lifetime) just before the eruption of the Kelud volcano in Indonesia on 14 February 2014 (Fig. 8). Radiative transfer calculations using OSIRIS-derived aerosol profiles indicate that the aerosol-caused errors in the results shown are less than $100 \mathrm{~m}$. We have therefore chosen to use equatorial RSAS data before the eruption to represent our best estimate of altitude registration errors (listed in Table 1).

Although we determined the best RSAS data point at the time just before the Kelud eruption, we investigated other locations and time periods to estimate the method's accuracy. The southern polar region is known to have relatively min- 
Table 1. RSAS results at the Equator before the Kelud eruption in February 2014. The time period had a minimum aerosol loading (during OMPS lifetime) and was chosen using OSIRIS measurements (Fig. 8).

\begin{tabular}{lccc}
\hline TH error, km & East & Center & West \\
\hline RSAS results & 1.12 & 1.37 & 1.52 \\
\hline
\end{tabular}

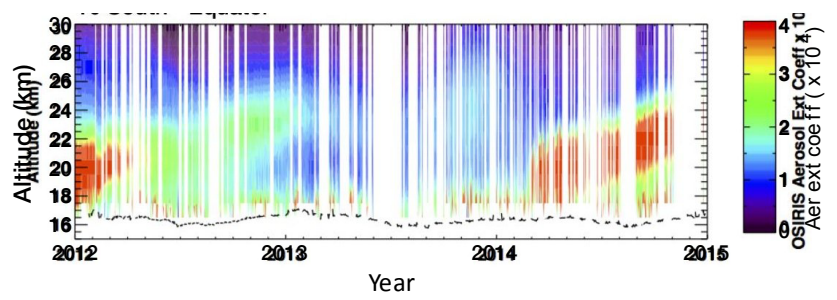

Figure 8. Time series of OSIRIS aerosol extinction profiles above the tropopause (dashed line). The large aerosol extinction coefficients in 2012 are due to the June 2011 Nabro eruption in Eritrea. The aerosols at $20 \mathrm{~km}$ reached a minimum value (during OMPS lifetime) just before the eruption of the Kelud volcano on 14 February 2014.

imal aerosol loading, especially during onset of the ozone hole in October, but the extreme viewing angles at the South Pole make the LS radiances difficult to model. The RSASderived $\mathrm{TH}$ errors in the southern polar region are greater than from the pre-Kelud time period results between 0 and $200 \mathrm{~m}$ for all slits. This range of RSAS results is used to estimate an absolute accuracy of $\pm 200 \mathrm{~m}$.

\subsection{ARRM results}

We calculated the radiances at $295 \mathrm{~nm}$ with the same radiative transfer code and profile inputs used for RSAS. The ARRM results presented here were normalized to RSAS results at the Equator before the Kelud eruption. The inter-slit differences have consequently been zeroed in all ARRM figures shown. We note that ARRM and RSAS estimates of the inter-slit TH differences agree to within $50 \mathrm{~m}$ at this normalization point.

Time-dependent plots show negative pointing error trends of approximately $200 \mathrm{~m}$ over the $\sim 5$ years of data (Fig. 9a). Much of this trend is the result of a known spacecraft pitch adjustment of $6 \operatorname{arcsec}(\sim 100 \mathrm{~m}$ in $\mathrm{TH})$ that occurred on 25 April 2013 and spacecraft inclination adjustment maneuvers during August and September 2014. We estimate the latter adjustment at $\sim 100 \mathrm{~m}$ with the same sign as the former. Accounting for these two shifts (Fig. 9b and c) largely removes any long-term pointing trend. Figure $9 \mathrm{a}$ also suggests that ARRM is sensitive to TH changes as small as $100 \mathrm{~m}$.

Figure 10 summarizes the ARRM time series over a range of latitudes and accounts for the two adjustments. At southern low to mid-latitudes variations are $\pm 70 \mathrm{~m}$. Seasonal vari-
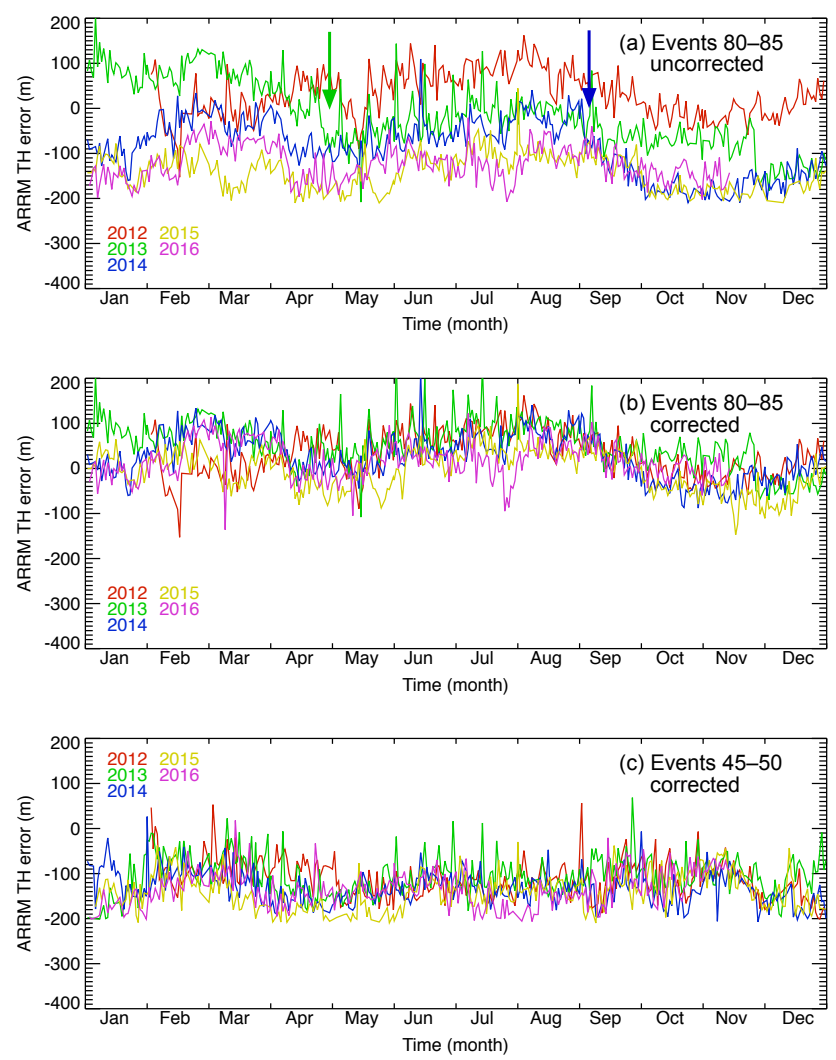

Figure 9. Daily averaged TH errors from ARRM analysis in bins of five events for the center slit over a year. Colors indicate a different year. (a) Event bin 80 to 85 ( equatorial) with no adjustment made for the distinct drop on 25 April 2013, when the spacecraft pitch was adjusted $\sim 6$ arcsec, or for an unconfirmed adjustment on 5 September 2014 resulting from inclination adjustment maneuvers. The drops are distinct, suggesting that ARRM may be able to detect TH changes of $\sim 100 \mathrm{~m}$ in the absence of other effects. (b) Event bin 80 to 85 ( equatorial) with the two adjustments included. (c) Event bin 45 to $50\left(\sim 45^{\circ} \mathrm{S}\right)$ with adjustments included shows a seasonal cycle of $\pm 70 \mathrm{~m}$. Remaining variations could be due to true pointing changes, errors in the GPH data that we used in our analysis, or variations in ozone.

ations are greatest at high latitudes (highest and lowest event bands), which may be in part a result of inadequate screening for PMCs. It is also possible that GPH or ozone errors are greater near the poles, or that the variations represent true pointing errors. As with RSAS, ARRM is sensitive to errors in $\mathrm{GPH}$ profile near $3 \mathrm{hPa}$ used for calculating $350 \mathrm{~nm}$ radiances at $40 \mathrm{~km}$ (see Sect. 4.1).

ARRM is designed to accommodate stray-light errors that are independent of wavelength. That is, no additional TH errors are mis-assigned when stray light at $65 \mathrm{~km}$ is the same at 295 and $350 \mathrm{~nm}$. The ground characterization of Limb sensor stray light indicates a small wavelength dependence (Jaross et al., 2014), but this is removed in ground processing. Our subsequent comparisons with RTM predictions indicate that residual stray-light errors at $65 \mathrm{~km}$ have a daily mean bias 

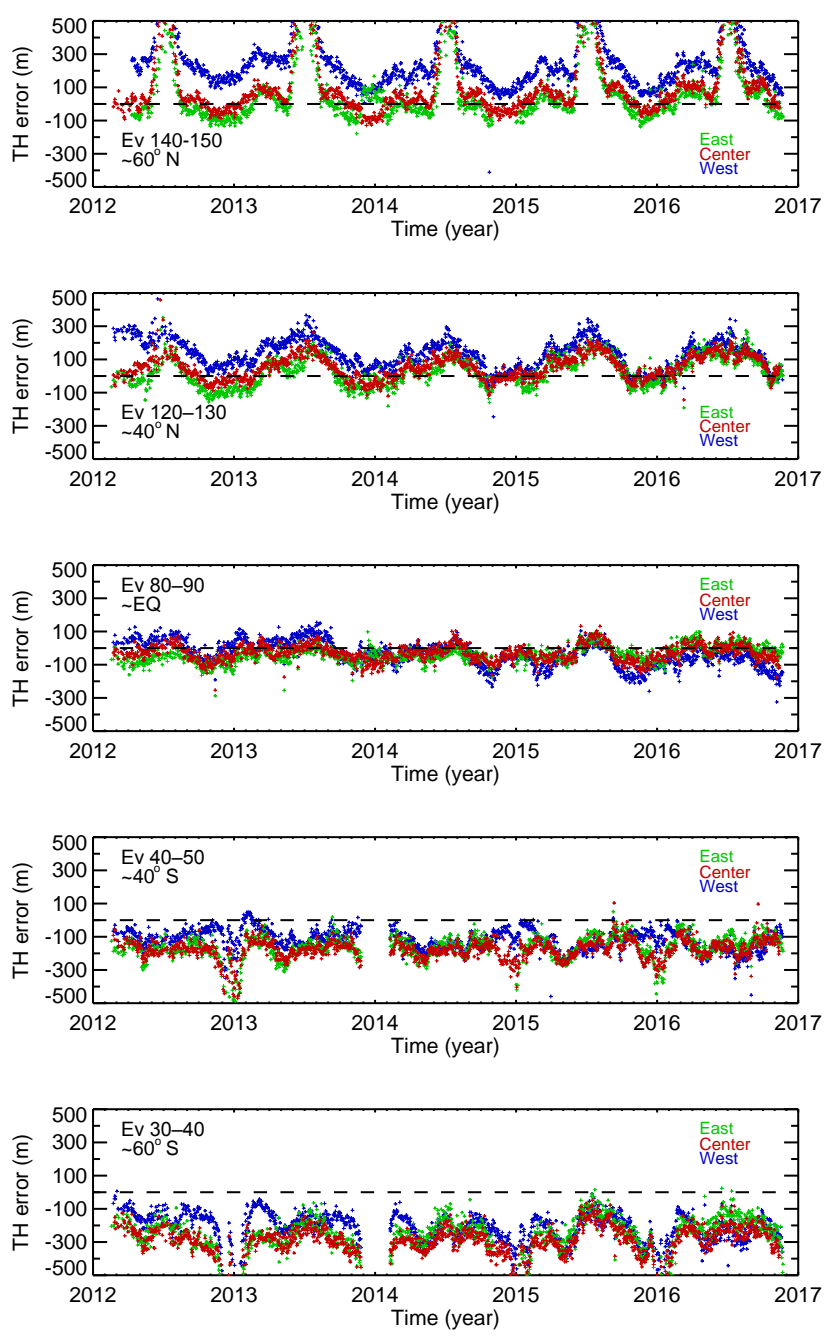

Figure 10. Daily averaged time-dependent plots of TH errors from ARRM analysis for the three slits. Approximate latitudes of the 10event band averages are noted. Values are normalized (by $\sim 200 \mathrm{~m}$ ) to the Equator just prior to the Kelud eruption on 14 February 2014 based on the RSAS results summarized in Table 1. Slit discrepancies and seasonal dependencies of $\pm 200 \mathrm{~m}$ can also be seen.

that translates to less than $100 \mathrm{~m}$ in TH. This sensitivity may be sufficient to explain the divergence of the west slit results in the northernmost panel of Fig. 10. This separation is seen more clearly in Fig. 11, which contains a mean of the ARRM results plotted as a function of time through each orbit. There are no geophysical errors that would give rise to inter-slit differences, but the west slit does have a known stray-light problem at high northern latitudes where direct solar illumination is near to the field of view (Jaross et al., 2014).

The more puzzling feature of Fig. 11 is the apparent 300$400 \mathrm{~m}$ variation in pointing through the course of each orbit. We lack indications of either geophysical or instrument errors to explain this result and must accept the possibility of a true pointing change. One potential explanation involves

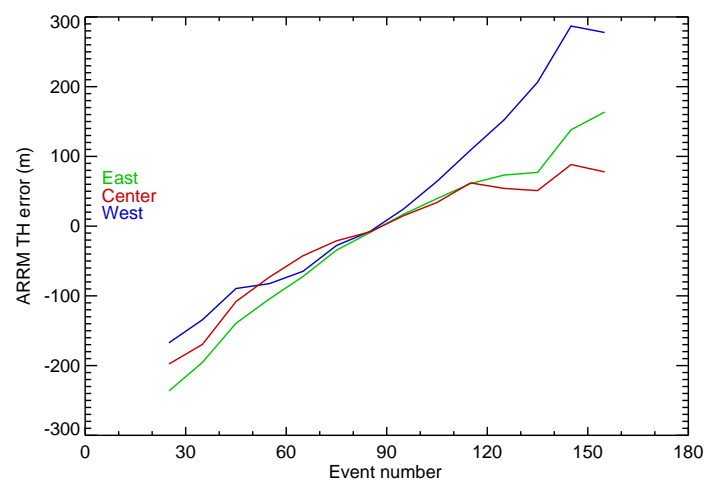

Figure 11. Average (over the $\sim 5$-year study period) ARRM results by event number (green: east slit; red: center slit; blue: west slit). There appears to be an average $300-400 \mathrm{~m}$ TH change over an orbit.

thermally induced flexing of the spacecraft that would affect the limb pointing but not the location of the slit image.

If the variation seen in Fig. 11 is attributed entirely to pointing errors, it implies that the slit edge analysis (see Fig. 7) underestimates the real changes by as much as $300 \mathrm{~m}$.

\section{Validation}

In this section we utilize uncertainties in the parameters used to derive $\mathrm{TH}$ to indirectly validate the results shown in Sect. 3. Section 4.1 focuses on the validation of $3 \mathrm{hPa} \mathrm{GPH}$ information from MERRA. In Sect. 4.2 we consider the sensitivity to DUR modeling errors. Finally, in Sect. 4.3 we compare the ozone mixing ratio at $3 \mathrm{hPa}$ derived from the OMPS LP and the Microwave Limb Sounder (MLS). For the validation studies in this section, the OMPS LP TH has been corrected with the RSAS errors listed in Table 1.

\subsection{GPH uncertainty}

Errors in the assumed GPH profile directly translate into TH errors. For ARRM, our application of the McGee technique depends upon the accuracy of the GPH at $3 \mathrm{hPA}(\sim 40 \mathrm{~km})$, and GPH errors in RSAS are greatest at $40 \mathrm{~km}$. So both RSAS and ARRM are affected by errors in the $3 \mathrm{hPA}$ GPH assumptions.

The MLS-MERRA differences provide an estimate of the errors caused by the use of MERRA GPH in our radiative transfer calculations. Fortunately, although the $3 \mathrm{hPA}$ GPH varies over $4 \mathrm{~km}$ along an orbit, a comparison of daily averaged values from MLS and MERRA show differences that are usually less than $200 \mathrm{~m}$ (Fig. 12).

These differences do not directly explain the orbital dependence of TH errors shown in Fig. 11 but do provide an estimate of the magnitude of errors caused by the use of MERRA GPH in our radiative transfer calculations. There is better ozone agreement at the poles, but this may be due to the reliance on climatology where there are scant measure- 

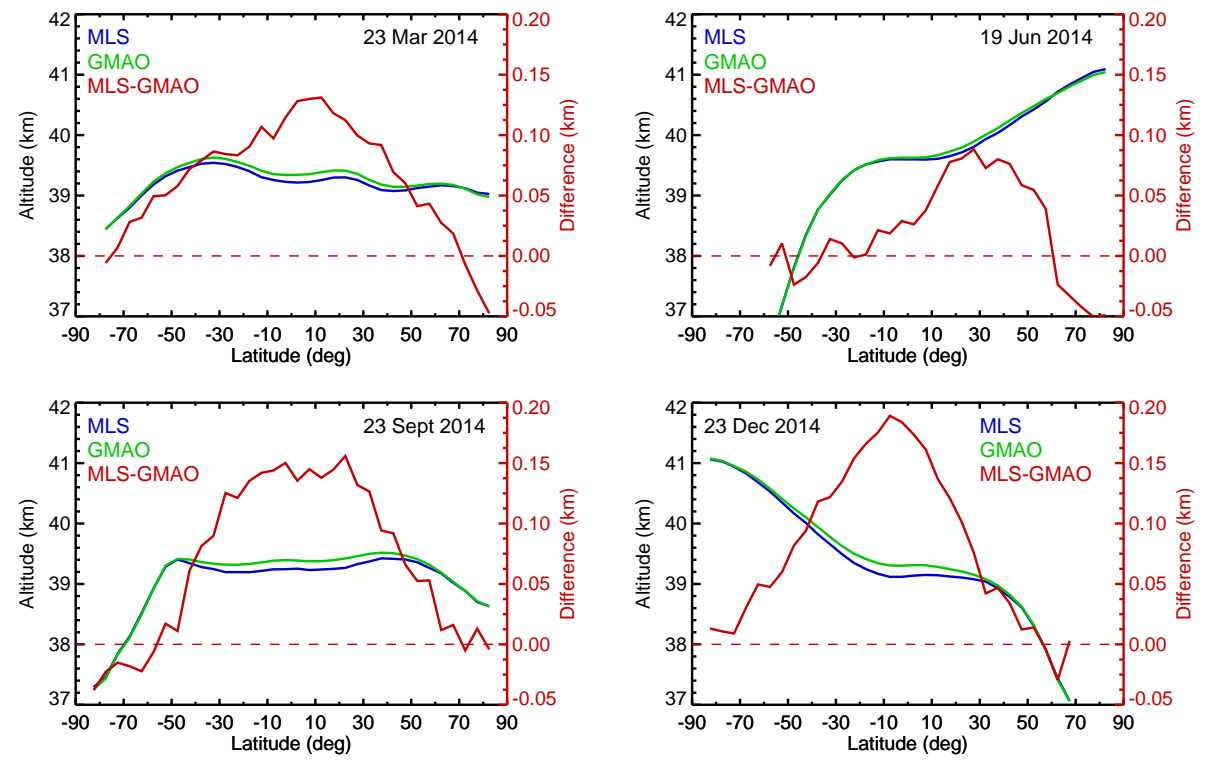

Figure 12. Daily $5^{\circ}$ zonal means of GPH from MLS (blue) and GMAO (green), and the difference MLS-GMAO (red) at $3 \mathrm{hPa}$ GPH for 4 cardinal days. Note that despite a $2-4 \mathrm{~km}$ change over an orbit, the differences are generally within $200 \mathrm{~m}$. These differences provide an estimate of the errors caused by the use of MERRA GPH in our radiative transfer calculations. Better agreement seen at the poles may simply be due to the fact that there are not many measurements at these latitudes and both may be influenced by the same climatology. If this error were attributed solely to the limb model and only at one altitude, the resulting TH error would be less than $\pm 200 \mathrm{~m}$. There is no evidence of either seasonal or north-south bias in the comparison, meaning that it is not clear how these GPH errors influence the ARRM results seen in Fig. 10 .

ments. If this error were attributed solely to the limb model and only at one altitude, the resulting TH error would be less than $\pm 200 \mathrm{~m}$.

There is no evidence of either seasonal dependence or north-south bias in the comparison, meaning that it is not clear how these GPH errors influence the ARRM results seen in Fig. 10. However, in Sect. 4.3 we discuss some suggestive but inconclusive results that help untangle GPH errors from TH errors.

\subsection{DUR modeling uncertainty}

The RSAS method and ARRM applied two strategies to minimize DUR modeling uncertainties. The RSAS method employs signal ratios in which the DUR effects largely cancel, and the ARRM uses $295 \mathrm{~nm}$ radiances for which ozone absorption screens the DUR signal. To ascertain the success of these strategies, we estimate the DUR modeling error by comparing LP measurements and modeled $350 \mathrm{~nm}$ radiances at $3 \mathrm{hPa}$. Model errors of the $350 \mathrm{~nm}$ radiances translate directly (Eqs. 1 and 3) into false estimates in the TH errors.

The OMPS Nadir instrument makes nearly simultaneous measurements from a smaller field of view $(50 \times 50 \mathrm{~km}$ at nadir). The surface reflectivity derived from its $340 \mathrm{~nm}$ radiances is therefore relatively insensitive to DUR effects compared to measurements derived from the LP measurements. These model-measurement comparisons provide an estimate of errors related to incomplete modeling of DUR and inhomogeneous surface albedo included in our RSAS and ARRM results. With better reflectivity assumptions the model-measurement comparisons offer a lower bound to the effect of DUR modeling errors.

The radiance comparison, shown in Fig. 13, suggests model or calibration errors of $2-3 \%$ on average, plus structures caused by the limb and nadir scene mismatch. If this error were attributed solely to the limb-modeled DUR effect, the resulting TH error would be less than $\pm 200 \mathrm{~m}$. There is no consistent latitude dependence in the 4 days of comparisons, meaning that DUR effects cannot explain the robust orbital variations seen in ARRM results (Fig. 11). It is possible that the DUR variations could explain the high-latitude seasonal variations seen in Fig. 10.

\subsection{Ozone comparison}

At $3 \mathrm{hPa}(\sim 40 \mathrm{~km})$ limb ozone retrievals are very sensitive to TH errors, with $20-25 \% \mathrm{~km}^{-1}$ change in ozone concentration (see Fig. 5). Similar to the knee method, we can use this sensitivity to gauge the residual TH errors. We compared LP ozone retrievals against Aura MLS v4 ozone retrievals at $3 \mathrm{hPa}$ (near $40 \mathrm{~km}$ ) (Fig. 14). While the latitudinal patterns of differences significantly vary with season, we find agreement within $\pm 10 \%$ over all seasons and latitude bands. If 

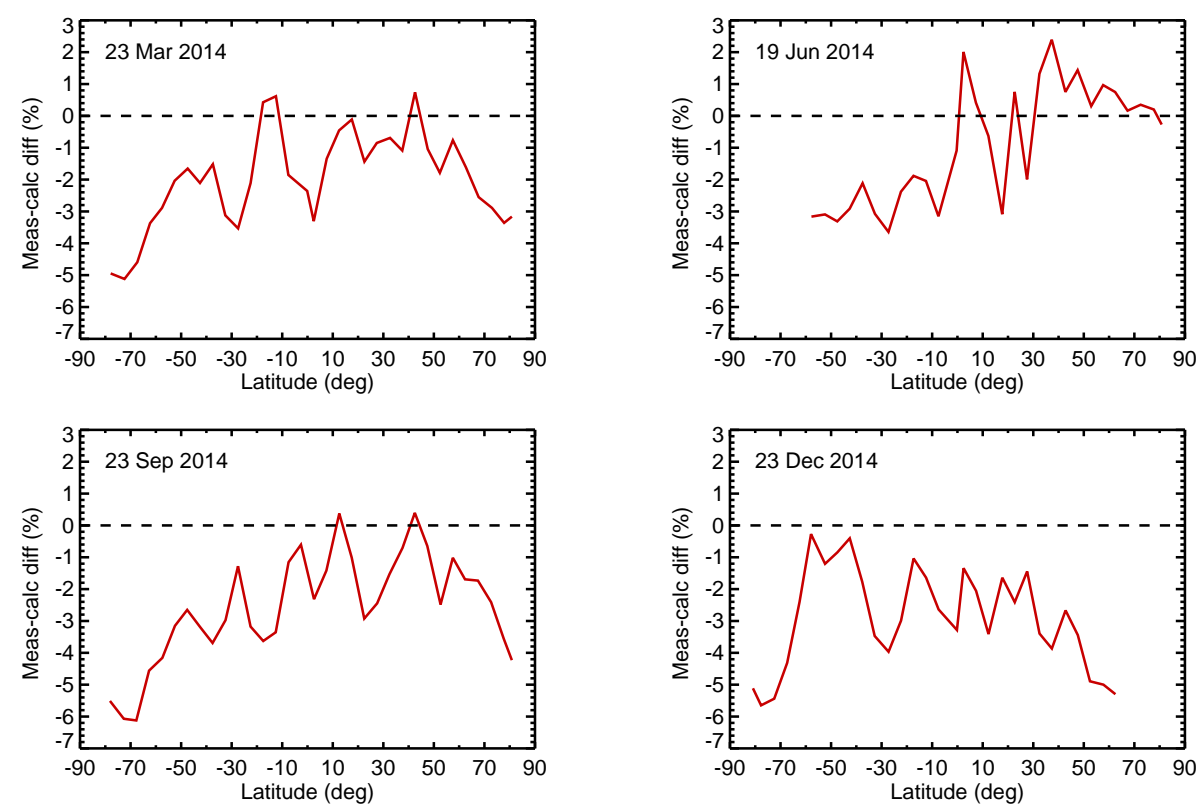

Figure 13. We have estimated the DUR modeling error by comparing $350 \mathrm{~nm}$ measured and modeled radiances at $3 \mathrm{hPa}$. The radiances are modeled using an independent, nearly simultaneous measure of surface reflectivity derived from the OMPS Nadir instrument at $340 \mathrm{~nm}$. The $50 \times 50 \mathrm{~km}$ nadir-view measurements are relatively insensitive to DUR effects. The radiance differences (given for the same 4 cardinal days as in Fig. 12) suggest model or calibration errors of $2-3 \%$ on average $( \pm 200 \mathrm{~m})$, plus structure caused by the contributing limb and nadir scene mismatch.
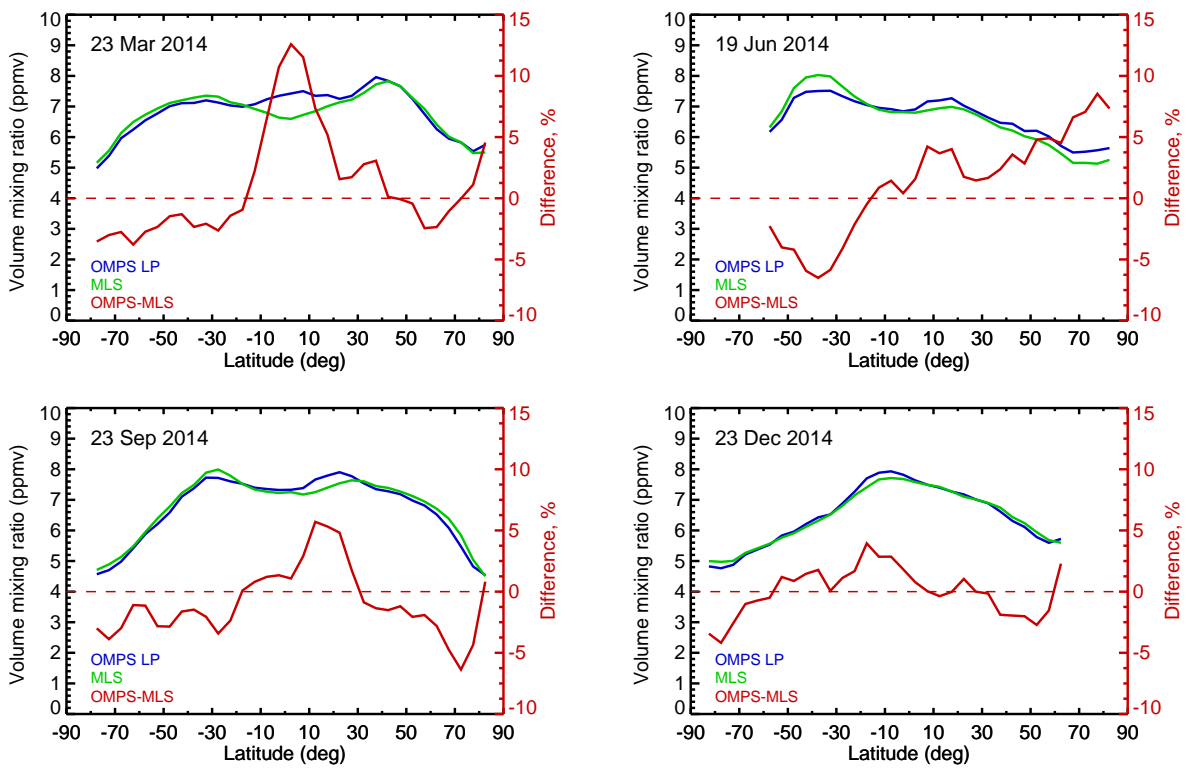

Figure 14. Daily $5^{\circ}$ zonal means of ozone from MLS (green) and OMPS LP (blue), and the MLS-OMPS LP differences (red) at $3 \mathrm{hPa}$ GPH for 4 cardinal days. The latitudinal patterns of differences significantly vary with season but are within $\pm 10 \%$ over all seasons and latitude bands. If completely interpreted as due to $\mathrm{TH}$ error, a $10 \%$ difference would translate to less than $500 \mathrm{~m}$ error.

completely interpreted as due to TH error, a $10 \%$ difference would translate to less than $500 \mathrm{~m}$ error.

The ARRM has displayed the ability to track any drifts or sudden changes of $100 \mathrm{~m}$ (Sect. 3.3), and time series of TH error derived from the ARRM track very closely to the time series of the LP-MLS $3 \mathrm{hPa}$ ozone differences (Fig. 15). Both ARRM and LP-MLS ozone comparisons depend upon accurate TH and MERRA information, and in the same way. So, while these results suggest some confidence in the ARRM technique, we cannot assign the correlation shown in Fig. 15 


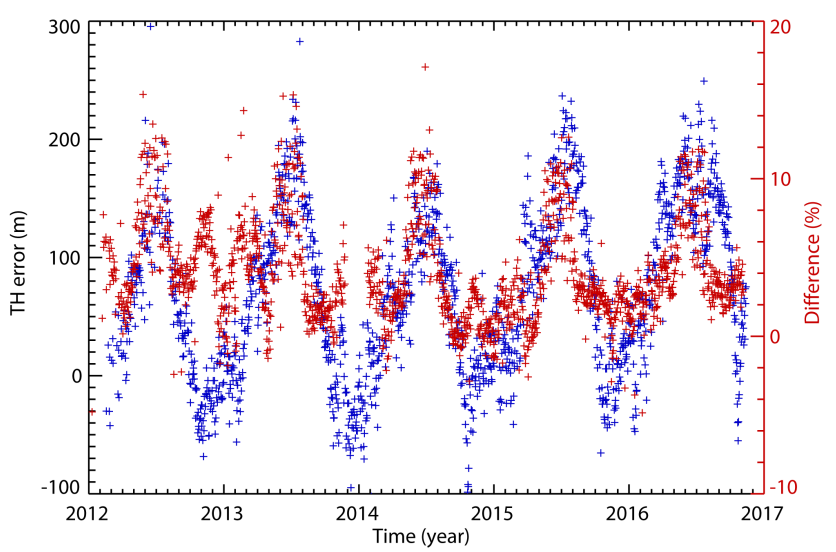

Figure 15. The time series of daily ARRM TH error (blue) and zonal mean ozone differences (\%) between OMPS LP and Aura MLS (red) at $50^{\circ} \mathrm{N}$ for the center slit. Note the similarity in timedependent patterns for ozone differences and $\mathrm{TH}$ error derived from AARM method. The fact that these two completely independent methods show very similar patterns gives us additional confidence in ARRM.

to only a TH error or a MERRA error. It is important to note that MLS ozone profiles are reported as volume mixing ratio on a vertical pressure grid, while the LP algorithm retrieves ozone as number density on an altitude grid. Thus, in order to compare LP and MLS ozone retrievals, we had to convert ozone number densities to mixing ratios using MERRA temperature and GPH profiles. This conversion inevitably introduces MERRA GPH and temperature errors into the ozone comparisons. Therefore ozone differences between LP and MLS ozone retrievals depend not only on the LP TH error but also on errors in MERRA GPH as well as on errors in the retrieval algorithms and instrumental sampling (geophysical noise). Furthermore, analysis of LP and MLS ozone retrievals indicates a large daily ozone variability at $3 \mathrm{hPa}$ that ranges from $2 \%$ in the tropics to $20 \%$ at high latitudes with the seasonal maximum during austral winters (results are not shown here); this analysis provides a sense of the geophysical ozone variability that is present. In consideration of all of the above factors, we remain cautious in making definite conclusions regarding applying the ARRM results; further analysis and comparisons with independent ozone observations (like SAGE III) are needed to confirm the results.

\section{Conclusions}

Accurate altitude registration is key to the success of using limb-scattered radiances to retrieve atmospheric trace gases. We have described two scene-based techniques that together provide highly precise and accurate estimates of the tangent height. These altitude registration techniques are inexpensive and more comprehensive than external sources of altitude information, such as star trackers mounted on the spacecraft. In fact the star trackers on the SNPP spacecraft failed to detect the $1-1.5 \mathrm{~km}$ tangent height error that we derived by applying the RSAS method (see Table 1). This error, if attributed to incorrect spacecraft pointing, means the nadir-viewing instruments on SNPP were locating scenes $340 \mathrm{~m}$ too far south. Initial pointing errors of even greater magnitude have been observed (Wolfe et al., 2013).

The RSAS and ARRM techniques are complementary. We developed the latter because changes in tangent height errors are rather more important than static errors. Figure 9 suggests the relative accuracy of ARRM is sufficient to detect $100 \mathrm{~m}$ changes in pointing in the absence of GPH errors. The accuracy may not be so small when GPH errors are included, especially for time periods less than 1 year. Our expectation is that multi-year trends in GPH error are small, a position that is supported by the lack of observed OMPS TH trends after accounting for distinct pointing shifts. RSAS too can be used to monitor pointing changes, but its sensitivity to stratospheric aerosols means the results may be influenced by geophysical processes such as volcanic eruptions.

\section{Data availability}

The data set is available here: http://dx.doi.org/10.5067/ suomi-npp/omps-limb/11-ev-grid/data12.

Acknowledgements. The authors gratefully acknowledge the assistance of NASA's limb processing team in providing the data used in this paper. We would also like to thank Dave Flittner, Ernest Nyaku, and Didier Rault, who helped with the development of and updates to the RT model. Finally, we would like to acknowledge the role Didier played in laying the groundwork for the OMPS limb retrieval algorithm.

Edited by: C. von Savigny

Reviewed by: two anonymous referees

\section{References}

Bourassa, A. E., Degenstein, D. A., Gattinger, R. L., and Llewellyn, E. J.: Stratospheric aerosol retrieval with optical spectrograph and infrared imaging system limb scatter measurements, J. Geophys. Res., 112, D10217, doi:10.1029/2006JD008079, 2007.

Janz, S. J., Hilsenrath, E., Flittner, D. E., and Heath, D. F.: Rayleigh scattering attitude sensor, Proc. SPIE, 146, 2831, doi:10.1117/12.257207, 1996.

Jaross, G., Bhartia, P. K., Chen, G., Kowitt, M., Haken, M., Chen, Z., Xu, P., Warner, J., and Kelly, T.: OMPS Limb Profiler instrument performance assessment, J. Geophys. Res.-Atmos., 119, 4399-4412, doi:10.1002/2013JD020482, 2014.

Kaiser, J. W., Von Savigny, C., Eichmann, K.-U., Noel, S., Bovensmann, H., and Burrows, J. P.: Satellite-pointing retrieval from atmospheric limb-scattering of solar UV-B radiation, Can. J. Phys., 82, 1041-1052, 2004. 
Llewellyn, E. J., Lloyd, N. D., Degenstein, D. A., Gattinger, R. L., Petelina, S. V., Bourassa, A. E., Wiensz, J. T., Ivanov, E. V., McDade, I. C., Solheim, B. H., McConnell, J. C., Haley, C. S., von Savigny, C., Sioris, C. E., McLinden, C. A., Griffioen, E., Kaminski, J., Evans, W. F., Puckrin, E., Strong, K., Wehrle, V., Hum, R. H., Kendall, D. J. W., Matsushita, J., Murtagh, D. P., Brohede, S., Stegman, J., Witt, G., Barnes, G., Payne, W. F., Piche, L., Smith, K., Warshaw, G., Deslauniers, D. L., MarcHand, P., Richardson, E. H., King, R. A., Wevers, I., McCreath, W., Kyrölä, E., Oikarinen, L., Leppelmeier, G. W., Auvinen, H., Megie, G., Hauchecorne, A., Lefevre, F., de La Noe, J., Ricaud, P., Frisk, U., Sjoberg, F., von Scheele, F., and Nordh, L.: The OSIRIS instrument on the Odin spacecraft, Can. J. Phys., 82, 411-422, 2004.

Loughman, R., Flittner, D., Nyaku, E., and Bhartia, P. K.: GaussSeidel limb scattering (GSLS) radiative transfer model development in support of the Ozone Mapping and Profiler Suite (OMPS) limb profiler mission, Atmos. Chem. Phys., 15, 3007-3020, doi:10.5194/acp-15-3007-2015, 2015.

McGee, T. J., Whiteman, D., Ferrare, R., Butler, J. J., and Burris, J.: STROZ LITE: Stratospheric ozone lidar trailer experiment, Opt. Eng., 30, 31-39, 1991.

McPeters, R. D., Janz, S. J., Hilsenrath, E., Brown, T. L., Flittner, D. E., and Heath, D. F.: The retrieval of $\mathrm{O}_{3}$ profiles from limb scatter measurements: Results from the Shuttle Ozone Limb Sounding Experiment, Geophys. Res. Lett., 27, 2597-2600, 2000.

Rault, D. F.: Ozone profile retrieval from Stratospheric Aerosol and Gas Experiment (SAGE III) limb scatter measurements, J. Geophy. Res., 110, D09309, doi:10.1029/2004JD004970, 2005.
Schwartz, M. J., Lambert, A., Manney, G. L., Read, W. G., Livesey, N. J., Froidevaux, L., Ao, C. O., Bernath, P. F., Boone, C. D., Cofield, R. E., Daffer, W. H., Drouin, B. J., Fetzer, E. J., Fuller, R. A., Jarnot, R. F., Jiang, J. H., Jiang, Y. B., Knosp, B. W., Krüger, K., Li, J.-L. F., Mlynczak, M. G., Pawson, S., Russell III, J. M., Santee, M. L., Snyder, W. V., Stek, P. C., Thurstans, R. P., Tompkins, A. M., Wagner, P. A., Walker, K. A., Waters, J. W., and Wu, D. L.: Validation of the Aura Microwave Limb Sounder temperature and geopotential height measurements, J. Geophys. Res, 113, D15S11, doi:10.1029/2007JD008783, 2008.

Sioris, C. E., Haley, C. S., McLinden, C. A., von Savigny, C., McDade, I. C., McConnell, J. C., Evans, W. F. J., Lloyd, N. D., Llewellyn, E. J., Chance, K. V., Kurosu, T. P., Murtagh, D., Frisk, U., Pfeilsticker, K., Bosch, H., Weidner, F., Strong, K., Stegman, J., and Megie, G.: Stratospheric profiles of nitrogen dioxide observed by Optical Spectrograph and Infrared Imager System on the Odin satellite, J. Geophys. Res., 108, 4215, doi:10.1029/2002JD002672, 2003.

Taha, G., Jaross, G., Fussen, D., Vanhellemont, F., Kyrölä, E., and McPeters, R. D.: Ozone profile retrieval from GOMOS limb scattering measurements, J. Geophys. Res., 113, D23307, doi:10.1029/2007JD009409, 2008.

von Savigny, C., Kaiser, J. W., Bovensmann, H., Burrows, J. P., McDermid, I. S., and Leblanc, T.: Spatial and temporal characterization of SCIAMACHY limb pointing errors during the first three years of the mission, Atmos. Chem. Phys., 5, 2593-2602, doi:10.5194/acp-5-2593-2005, 2005.

Wolfe, R. E., Lin, G., Nishihama, M., Tewari, K. P., Tilton, J. C., and Isaacman, A. R.: Suomi NPP VIIRS prelaunch and on-orbit geometric calibration and characterization, J. Geophys. Res.-Atmos., 118, 11508-11521, doi:10.1002/jgrd.50873, 2013. 